\title{
OS DESAFIOS ENFRENTADOS PELOS PROFESSORES DA EDUCAÇÃO DE JOVENS E ADULTOS DIANTE DO PROCESSO DE AVALIAÇÃO DA APRENDIZAGEM DOS ALUNOS
}

\author{
THE CHALLENGES FACED BY TEACHERS OF YOUTH AND ADULT \\ EDUCATION IN THE EVALUATION PROCESS OF STUDENTS' LEARNING
}

\author{
LOS DESAFÍOS ENFRENTADOS POR LOS PROFESORES DE LA EDUCACIÓN \\ DE JÓVENES Y ADULTOS FRENTE AL PROCESO DE EVALUACIÓN DEL \\ APRENDIZAJE DE LOS ALUMNOS
}

\author{
Regina Magna Bonifácio de Araújo \\ Doutora em Educação - Professora na UFOP \\ E-mail: regina.magna@hotmail.com
}

\author{
Mayara Carvalho Martins \\ Mestre em Educação pela UFOP - Professora na UFV \\ E-mail: mayarinhacmartins@yahoo.com.br
}

\begin{abstract}
RESUMO
Esta investigação encontra-se no entrecruzamento de duas temáticas: avaliação da aprendizagem e Educação de Jovens e Adultos e consiste na apresentação dos resultados de uma pesquisa que objetivou compreender como vêm se dando no campo educacional as práticas avaliativas dos professores dos anos iniciais dessa modalidade. De abordagem qualitativa, este estudo usou como instrumento de organização de dados a entrevista semiestruturada. Os resultados evidenciaram os desafios enfrentados pelos docentes, dentre eles, a falta de material didático específico como, por exemplo, livro didático e atividades pedagógicas que contextualizem o conteúdo às vivências dos educandos; a dificuldade do professor em desconstruir as representações de escola tradicional que os alunos trazem para a sala de aula e, por fim, a dificuldade do ofício docente, que vai muito além do domínio de conteúdos e conhecimentos pedagógicos. A conclusão da investigação indica a necessidade de ampliação das discussões em torno da avaliação na EJA.
\end{abstract}

Palavras-chave: Avaliação. Educação de Jovens e Adultos. Avaliação na EJA. Desafios docentes.

\footnotetext{
ABSTRACT

This research is at the intersection of two themes: the assessment of learning and the education of youth and adults, and consists of presenting the results of a research that aimed to understand how the evaluation practices of teachers of the early years of this modality of education have been taking place in the educational field. This qualitative study used
} 
semi-structured interview as a tool for data organization. The results showed the challenges faced by teachers, among them, a) the lack of specific didactic material, such as textbooks and pedagogical activities that contextualize the content to the students' experiences; b) the difficulty of the teacher to deconstruct the representations of traditional school that the students bring to the classroom and, finally, c) the difficulty of the teaching profession, which goes far beyond the mastery of pedagogical contents and knowledge. The conclusion of the investigation indicated the need for further discussion about the evaluation in the EJA.

Keywords: Evaluation. Youth and Adult Education. Evaluation at EJA. Challenges. Teacher.

\section{RESUMEN}

Esta investigación se encuentra en la intersección de dos temas: la evaluación del aprendizaje y la educación de jóvenes y adultos y consiste en presentar los resultados de una investigación que tuvo como objetivo comprender cómo las prácticas de evaluación de los docentes de los primeros años de esta modalidad se llevaron a cabo en el campo educativo. Desde un enfoque cualitativo, este estudio utilizó como herramienta de organización de datos la entrevista semiestructurada. Los resultados mostraron los desafíos que enfrentan los maestros, entre ellos, la falta de material didáctico específico, como libros de texto y actividades pedagógicas que contextualizan el contenido a las experiencias de los estudiantes; la dificultad del maestro para desconstruir las representaciones de la escuela tradicional que los alumnos traen para el aula $\mathrm{y}$, finalmente, la dificultad de la profesión docente, que va mucho más allá del dominio de los contenidos y conocimientos pedagógicos. La conclusión de la investigación indicó la necesidad de la ampliación de la discusión sobre la evaluación en la EJA.

Palabras clave: Evaluación. Educación de jóvenes y adultos. Evaluación en EJA. Desafíos Maestro.

\section{INTRODUÇÃO}

Voltada a jovens e adultos que não tiveram, na idade apropriada, oportunidade de acesso ou mesmo de continuidade nos estudos, a Educação de Jovens e Adultos (EJA) é uma modalidade da Educação Básica que garante o direito à formação, proporcionando ao aluno a oportunidade de elevar sua escolaridade, garantida como direito do cidadão e dever do Estado pela Constituição de 1988. Vale ressaltar a concepção ampliada da Educação de Jovens e Adultos no sentido de não se limitar apenas à escolarização, mas também de reconhecer a educação como meio de (re) integração social e econômica e formação de sujeitos críticos e ativos, frente à própria realidade. E essa modalidade vem adquirindo maior visibilidade no campo educacional, ressaltando sua relevância, como espaço de sociabilidade, reinserção 
social e conhecimento. Portanto, pensar a EJA como um todo, buscando refletir não só o acesso e atendimento desses alunos, mas também a necessidade de pensar intervenções e procedimentos que levem em consideração as especificidades do seu público atendido, é um fator indispensável que deve ser considerado na construção de propostas e projetos que buscam atender essa modalidade de maneira mais singular.

Em razão de tais apontamentos, o presente trabalho apresenta resultados parciais de uma pesquisa, já concluída, que objetivou investigar as práticas avaliativas utilizadas pelos professores da EJA em classes dos anos iniciais do Ensino Fundamental da rede pública dos municípios que compõem a Região dos Inconfidentes ${ }^{1}$, em Minas Gerais. O intuito deste texto consiste em apresentar os desafios que os professores dessa modalidade enfrentam em sua prática cotidiana ao elaborarem os processos de ensino e aprendizagem, bem como ao lidarem com a avaliação da aprendizagem. Em vista das possíveis contribuições e da relevância desta investigação, vale ressaltar que os estudos acerca da avaliação na EJA podem colaborar ao acrescentar conhecimento e reflexões ao campo da educação de pessoas jovens, adultas e idosas.

Este texto está organizado em cinco seções; nesta seção, a Introdução, trata do tema, objeto, objetivo geral, justificativa e relevância da pesquisa. Na segunda seção, Referencial teórico, são destacados os aportes teóricos da pesquisa; na terceira seção, Metodologia da pesquisa, será descrito o caminho metodológico para esta investigação. Na quarta seção, Descrição e análise dos dados, serão apresentados os resultados e as considerações construídas a partir das análises dos dados. Por fim, na quinta seção, Conclusão, são retomados os aspectos introdutórios, demonstrando o caminho percorrido para se chegar ao objetivo, as colocações finais, que não pretendem ser conclusivas, mas que se propõem a fomentar o debate acerca dos processos avaliativos na Educação de Jovens e Adultos.

\section{REFERENCIAL TEÓRICO}

Segue abaixo o conteúdo teórico que embasa esta pesquisa.

\subsection{O PROCESSO DE AVALIAÇÃO}

\footnotetext{
${ }^{1}$ A Região dos Inconfidentes é a denominação dada aos municípios que compõem a Superintendência Regional de Ensino de Ouro Preto: Mariana, Acaiaca, Itabirito, Diogo de Vasconcelos e Ouro Preto, localizados no Estado de Minas Gerais.
} 
A avaliação sempre despertou o interesse de pesquisadores e educadores, em todos os segmentos da educação. Compreendida como um instrumento que orienta e acompanha o processo educacional, hoje ela contrapõe-se ao modelo avaliativo com sentido de julgamento e, em consequência, de exclusão e reprovação dos seus alunos. As práticas avaliativas, ao se desvincularem dos modelos pautados apenas em aspectos técnicos e quantitativos, podem contribuir para a construção de uma cultura escolar guiada para o desenvolvimento e a aprendizagem e não para as notas.

O conhecimento não tem sentido em si mesmo: deve ajudar a compreender o mundo, e nele intervir. Assim sendo, entendemos que a principal finalidade da avaliação no processo escolar é ajudar a garantir a formação integral do sujeito pela mediação do conhecimento, a aprendizagem por parte de todos os alunos (VASCONCELLOS, 2008, p.57).

Portanto, refletir e construir uma prática avaliativa implica na decisão de escolher procedimentos relacionados ao processo de ensino e aprendizagem para, com isso, corrigir, refletir e melhorar a ação educativa em sala de aula. O que orienta para uma a avaliação pautada em uma perspectiva mais democrática de educação, mais inclusiva quanto às diferentes aprendizagens que ocorrem num espaço escolar.

Segundo Barcelos (2014), avaliar é perceber e compreender o que da nossa prática educativa não foi suficiente para fazer com que os alunos aprendam. Entretanto, convivemos ainda com uma avaliação que busca aquilo que os alunos não aprenderam, ou aquilo que eles erraram por qualquer outro motivo. $\mathrm{O}$ autor propõe uma lógica inversa a essa:

\footnotetext{
É neste sentido que sugiro (1) que busquemos nos resultados das nossas avaliações, o que foi entendido daquilo que queríamos que eles (as) - os (as) educandos entendessem; (2) num segundo momento buscar refazer o percurso do entendimento feito pelos educandos e (3) após estes dois procedimentos dedicar uma especial atenção para aqueles pontos que ficaram sem entendimento ou foram motivadores de dúvidas para a comunidade de aprendizagem ${ }^{2}$ (BARCELOS, 2014, p.3).
}

Essa proposta do autor, ao mudar a forma de avaliar, tem como consequência uma divisão de responsabilidades em relação ao sucesso ou fracasso do processo de ensino e aprendizagem. Dessa maneira, professores e alunos têm o mesmo compromisso em relação à prática avaliativa e aos seus resultados. Segundo esse mesmo autor, o desafio que está posto para os docentes em relação à avaliação consiste em repensar o ato avaliativo, deixando de lado as “certezas" estabelecidas previamente. Além disso, valoriza a participação do educando nesse

\footnotetext{
${ }^{2} \mathrm{O}$ autor recorre à proposta de Paulo Freire. Nessa perspectiva, não se separa no grupo aquele que ensina daquele que aprende. Na comunidade de aprendizagem, quem ensina aprende e quem aprende ensina.
} 
processo e o responsabiliza também pela sua construção do conhecimento e pelo seu desenvolvimento.

Nesse contexto, o processo de ensino influencia a maneira de avaliar, assim como o avaliar direciona o ensino. Esse processo também influencia o comportamento do aluno e sua postura diante do conhecimento e da aprendizagem. Daí a importância de considerar que a tarefa do professor não é apenas atribuir notas, mas garantir o aprendizado dos alunos, utilizando de uma avaliação que mostre ao aluno o que ele aprendeu e quais as suas dificuldades, dando-lhe a oportunidade de retomar o processo de aprendizagem, tentando melhorar e aperfeiçoar seu conhecimento, ou seja, envolvendo-se no compromisso com a sua própria formação.

\subsection{O PROCESSO DE AVALIAÇÃO NA EJA}

Na EJA, trabalhamos com pessoas que já trazem marca de exclusão e rejeição da escola, são sujeitos que, muitas vezes, já vivenciaram a experiência escolar e foram excluídos da escola, por diversos motivos. Barcelos $(2014$, p.27) destaca que, ao não resolvermos as questões pertinentes ao ato avaliativo (reprovação/ não aprendizagem), “estamos, em última instância, negando a potencialidade da escola como uma instituição fundamental a qualquer sociedade nos moldes em que vivemos atualmente". Fundamental na perspectiva de um direito básico, o direito à educação é, mais que isso, o direito de dar ao sujeito a oportunidade de se ver como ator social, que sabe da importância que tem na sociedade em que vive e sabe do seu papel de reivindicação e de participação política. Nesse sentido, a tomada de consciência e a compreensão de nossas práticas educativas requerem uma reflexão sistemática e bem fundamentada.

Sobre esse aspecto, para Freire (1989), a prática docente e a avaliação têm uma relação substancial. Ele considera ainda que o trabalho de avaliar a prática jamais deixa de acompanhá-la, “o trabalho de avaliar a prática jamais deixa de acompanhá-la. A prática precisa de avaliação como os peixes precisam de água e a lavoura da chuva " (p.47). E completa:

[...] Não é possível praticar sem avaliar a prática. Avaliar a prática é analisar o que se faz, comparando os resultados obtidos com as finalidades que procuramos alcançar com a prática. A avaliação da prática revela acertos, erros e imprecisões. A avaliação corrige a prática, melhora a prática, aumenta a nossa eficiência (FREIRE, 1989, p.47). 
Nessa visão, portanto, refletir e construir uma prática avaliativa implica a decisão de escolher procedimentos relacionados ao processo de ensino e aprendizagem para, com isso, corrigir, refletir e melhorar a ação educativa em sala de aula. Dessa maneira, a avaliação deveria estar pautada em uma perspectiva mais democrática de educação.

Outro fator relevante a ser destacado diz respeito à configuração do sistema educacional imbricado nos fatores burocráticos. A avaliação, incluída nesse contexto, é rodeada por leis, pareceres, resoluções, enfim, é imbuída de exigências e determinações legais às escolas e aos professores. Ter consciência desses aspectos e das exigências colocadas pelas políticas públicas é imprescindível para repensar e reconstruir o significado da avaliação pautada em uma concepção democrática.

Os professores estão por demais preocupados com suas metodologias. Seguidamente solicitam "receitas de avaliação". No entanto, de nada valem as orientações metodológicas se não estiverem fundamentadas em uma concepção libertadora de avaliação. O "como fazer" é decorrente do "por que fazer". Então, a pergunta fundamental é: "Por que avaliamos"? ou "A serviço de quem avaliamos"? (HOFFMAN, 1993, p.114).

Sob esta ótica, sem uma perspectiva teórica e metodológica da prática educativa a serviço da aprendizagem, os processos avaliativos persistirão em afirmar que o sujeito que não aprende os conteúdos previamente fixados, no tempo em que a instituição determina, estão fadados ao fracasso e devem ser reprovados até que esses consigam acompanhar o ritmo fixado pela escola. Esse é um problema do uso da avaliação como um instrumento de discriminação e seleção social, na medida em que assume, no âmbito da escola, a tarefa de separar os "aptos" dos "inaptos", os “capazes" dos "incapazes".

Nesse sentido, o ato avaliativo torna-se o um processo em que alguns educandos são incluídos e outros, não. Este fato evidencia que avaliar é também um ato político, como destaca Vasconcellos (2008, p.37):

O caráter político da avaliação se traduz concretamente na possibilidade de reprovação do aluno. A avaliação não seria este "bicho de sete cabeças", se não houvesse o respaldo legal para a reprovação do aluno por parte do professor. Objetivamente, no sistema educacional, a avaliação é hoje o instrumento de controle oficial, o "selo" do sistema, o respaldo legal para a reprovação/aprovação, para o certificado, para o diploma, para a matrícula.

Do ponto de vista político-pedagógico, esta é uma prática antidemocrática, pois está pautada no profissional docente e na instituição de ensino, não levando em conta o sujeito aprendiz. 
Portanto, um dos grandes desafios é a construção de novos caminhos, que conduzam os professores dessa modalidade a avaliarem de forma mais flexível, considerando os conhecimentos prévios dos alunos, visando a formar cidadãos críticos, reflexivos e participativos na sociedade. Nesse contexto, o processo de ensino influencia a maneira de avaliar, assim como avaliar direciona o ensino. Esse processo também influencia o comportamento do aluno e sua postura diante do processo de aprendizagem.

Daí a importância de considerar que a tarefa do professor não é apenas atribuir notas, mas garantir o aprendizado dos alunos, utilizando de uma avaliação que mostre ao aluno o que ele aprendeu e quais as suas dificuldades, dando-lhe a oportunidade de retomar o processo de aprendizagem, tentando melhorar e aperfeiçoar seu conhecimento, ou seja, envolvendo-se no compromisso com a sua própria formação.

\section{METODOLOGIA DA PESQUISA}

Vale ressaltar que antes de dar início à investigação, o projeto foi enviado para aprovação na Plataforma Brasil. Mediante a aprovação e definido o campo de coleta de dados, todos os sujeitos participantes da pesquisa assinaram um Termo de Consentimento Livre e Esclarecido (TCLE), confirmando a sua adesão voluntária e autorizada formalmente.

Mediante a problemática de investigar as práticas avaliativas dos professores da Educação de Jovens e Adultos, a fim de coletar dados e informações para o aporte da mesma, optamos por trabalhar com a abordagem predominantemente qualitativa. Essa abordagem, segundo Bogdan e Biklen (1994), tem sido contemplada cada vez mais no campo educacional devido a suas características, que advêm de questões que se dão por investigar fenômenos dentro da sua complexidade em seu próprio contexto, ou seja, tentar compreender o comportamento dos sujeitos por meio das suas próprias concepções.

A metodologia de abordagem qualitativa é uma investigação de caráter descritivo, portanto a sua produção de dados se dá por meio da fala dos sujeitos ou da observação da sua postura e posicionamentos. Há nessa abordagem uma diversidade de estratégias investigativas, pois no campo da educação ela pode assumir diversas maneiras e se insere em diferentes contextos. A opção pela abordagem qualitativa justifica-se pelo fato de considerar os sujeitos participantes como fonte de conhecimentos, por meio das suas opiniões, pensamentos e atitudes. 
As características acima descritas corroboram com a investigação acerca das práticas avaliativas utilizadas pelos professores da EJA. Para isso, as ferramentas metodológicas utilizadas, para conduzir a investigação, foram o questionário e a entrevista semiestruturada. O questionário teve como objetivo caracterizar os interlocutores da pesquisa quanto à formação inicial, tempo na carreira, tempo de atuação na EJA, formação continuada e escolha ou não por trabalhar nessa modalidade, e com a entrevista buscou-se compreender o que os professores pensam e como agem, os significados dentro do contexto escolar que atribuem à avaliação ${ }^{3}$.

As entrevistas foram transcritas na íntegra, ou seja, de acordo com a gramática do falante incluindo os risos, pausas, hesitações, entre outras manifestações, tanto do entrevistador como do entrevistado. A investigação foi realizada em 5 (cinco) escolas municipais de Educação Básica, que compõem a 25ª Superintendência Regional de Ensino de Ouro Preto, localizadas na Região dos Inconfidentes e que oferecem os anos iniciais do Ensino Fundamental. A seleção dos participantes seguiu os seguintes critérios: localização geográfica, ou seja, a proximidade onde a pesquisa foi desenvolvida; e série em que os professores atuavam, os anos iniciais do Ensino Fundamental. A investigação contou com 8 (oito) docentes, e com o objetivo de preservar o anonimato, o nome dos participantes foram substituídos por códigos fictícios.

Para a análise dos dados sistematizados a partir do questionário e das entrevistas, utilizamos o método de análise de conteúdo. Diversos autores apresentam formas de trabalhar com os dados, porém, optamos nesta pesquisa por trabalhar com os dados a partir da análise de conteúdo, com base na metodologia proposta por Bardin (2011), Esteves (2006) e Lima (2006). Optamos por este procedimento devido ao reconhecimento do papel ativo do interlocutor na produção do conhecimento. Além disso, acreditamos que a análise de conteúdo se adéqua melhor à natureza dos dados coletados. Na pesquisa, os dados são suscitados pelo pesquisador e o ponto central é a fala, por meio da entrevista, levando em conta a mensagem que essa fala traz a sua finalidade, o conteúdo que ela carrega, tendo como base a inferência, que será efetuada por meio de indicadores de frequência.

\section{DESCRIÇÃO DOS RESULTADOS}

\footnotetext{
${ }^{3}$ Nesta investigação, para manter a privacidade dos participantes, eles serão identificados com pseudônimos.
} 
Para compreender o contexto das práticas avaliativas na Educação de Jovens e Adultos, faz-se necessário considerar os diversos elementos do ato pedagógico que nela estão inseridos, como: professor, aluno, currículo, escola, prática educativa e demais aspectos que contribuem para que se efetive a avaliação a serviço da aprendizagem dos educandos.

Os primeiros dados dessa investigação, de caráter exploratório, foram obtidos por meio do questionário de perfil aplicado aos sujeitos participantes. A seguir, é apresentado um quadro detalhado com os dados de todas as professoras, com o intuito de identificar e contextualizar as falas na análise de dados.

\section{QUADRO 1 - Caracterização dos sujeitos da pesquisa}

\begin{tabular}{|c|c|c|c|c|c|c|c|}
\hline & GÊENERO & $\begin{array}{c}\text { SERIE } \\
\text { QUE } \\
\text { ATUA } \\
\text { NA EJA }\end{array}$ & FORMAÇÃO & $\begin{array}{c}\text { TEMPO DE } \\
\text { TRABALHO } \\
\text { COM A EJA }\end{array}$ & $\begin{array}{c}\text { TEMPO DE } \\
\text { TRABALHO EM } \\
\text { OUTROS } \\
\text { SEGMENTOS }\end{array}$ & $\begin{array}{c}\text { TEM FEITO } \\
\text { CURSOS } \\
\text { SOBRE A EJA }\end{array}$ & $\begin{array}{c}\text { ESCOLHEU } \\
\text { TRABALHAR } \\
\text { COM A EJA }\end{array}$ \\
\hline Adriana & Fem & $1^{\circ}$ ao $4^{\circ}$ & Letras & 02 anos & 15 anos & Não & Sim \\
\hline Diana & Fem & $1^{\circ}$ & Pedagogia & 06 meses & Nenhum & Sim & Sim \\
\hline Dulce & Fem & $2^{\circ} 3^{\circ}, 4^{\circ}$ & Pedagogia & 05 anos & Nenhum & Sim & Sim \\
\hline Inês & Fem & $1^{\circ}$ & Pedagogia & 22 anos & 27 anos & Sim & Sim \\
\hline Ivone & Fem & $3^{\circ} \mathrm{e} 4^{\circ}$ & $\begin{array}{c}\text { Magistério } \\
\text { Superior }\end{array}$ & 18 anos & 14 anos & Sim & Sim \\
\hline Manuela & Fem & $1^{\circ}$ e $2^{\circ}$ & $\begin{array}{c}\text { Magistério } \\
\text { Superior }\end{array}$ & 03 meses & 25 anos & Não & Sim \\
\hline Maria & Fem & $1^{\circ}$ & Pedagogia & 03 meses & Nenhum & Não & Não \\
\hline Olga & Fem & $3^{\circ}$ & $\begin{array}{l}\text { Magistério } \\
\text { Superior }\end{array}$ & 14 anos & 32 anos & Sim & Sim \\
\hline
\end{tabular}

Fonte: elaborado pelas autoras (2016)

A reflexão feita a partir dos dados dos questionários em relação ao perfil docente trouxe alguns indicadores que chamaram a atenção: a recente atuação de alguns docentes na educação de jovens e adultos, a formação contínua dos docentes e os motivos de estarem atuando nesta modalidade.

No decorrer desta investigação, tentamos compreender a avaliação da aprendizagem praticada na Região dos Inconfidentes também por meio do discurso dos professores da EJA dos anos iniciais do Ensino Fundamental. Todo esse processo será agora discutido por meio das vozes dos atores responsáveis pelo trabalho educativo e pedagógico nessa modalidade de ensino. Procuramos, nesse texto, analisar os desafios e as possibilidades da avaliação na EJA.

Com o auxílio dos depoimentos dos professores entrevistados, analisamos de forma mais aprofundada o cotidiano dos sujeitos dessa modalidade educativa, como os estudantes se comportam diante do processo avaliativo e dentro da sala de aula e também a forma como os professores atuam e se relacionam com os educandos. 
As respostas dos professores à entrevista proposta nesta investigação revelaram aspectos importantes vivenciados na prática educativa que podem consistir em entraves e desafios para uma avaliação de qualidade e, sobretudo, para a avaliação na EJA. Dentre esses desafios, podemos citar a falta de material específico; o conflito entre a prática pedagógica do professor e as representações de escola e dos processos de ensino dos alunos da EJA; os diferentes níveis de conhecimento dos alunos; a aproximação dos conteúdos das vivências cotidianas dos educandos. Esses se constituíram em alguns dos aspectos levantados pelos professores e que nessa seção serão apresentados. Ao refletirmos sobre os desafios dos professores ao avaliar na EJA, faremos também algumas considerações sobre os desafios do processo de ensino, pois a avaliação é uma das diversas dimensões da ação educativa.

Dentre os desafios revelados nos discursos das educadoras, participantes desta pesquisa, um deles diz respeito à falta de material didático específico para se trabalhar com os alunos da EJA, como ressalta a professora S01: "Eu acho que está faltando. Falta de material pra aquele, pra aquela faixa ali, porque não tem aquele material pra eles, entendeu”.

A preocupação em relação ao material didático para a EJA também perpassou as reflexões da professora S02:

Porque a gente não tem muito material pra trabalhar com os adultos, a dificuldade mais é essa, porque assim o adulto é muito diferente da criança, a gente não pode estar dando coisa pra adulto que nem pra criança, igual pra alfabetizar, para o adulto é completamente diferente, a gente não vai dar um brinquedo pra ele nem nada. Eu acho que é o material (S02).

Essa fala evidencia o material didático como um recurso que contribui para a prática educativa docente em sala de aula e ainda traz elementos acerca da compreensão que a professora Diana possui de que a prática pedagógica nessa modalidade de ensino se diferencia da prática do ensino regular. Muitas vezes o docente elabora os próprios materiais que utiliza em sala de aula, ou até mesmo, reaproveita e readapta materiais do ensino regular para a EJA. Esta afirmação pode ser confirmada pela pesquisa feita por Guimarães e Martins (2014), que procuravam identificar quais eram as práticas pedagógicas dos professores dos anos iniciais da EJA. Dentre os resultados de tal estudo, destacamos:

Todas as professoras fazem uso de diversos recursos em suas aulas, entre eles, jogos, atividades xerocadas, livros, entre outros. Nenhum desses materiais, segundo elas é próprio da EJA, por isso, a professoras têm que adaptar e reaproveitar alguns materiais do ensino regular......] Quando as professoras necessitam de algum material, ambas responderam que recorrem à internet $\mathrm{e}$ aos colegas de trabalho. Afirmaram ainda que utilizam e buscam outros tipos de recursos para melhorar e diversificar as aulas, visando facilitar a aprendizagem dos alunos, frente à falta de 
material específico para essa modalidade de ensino (GUIMARÃES; MARTINS, 2014, p.25).

O material didático pode ser um material fundamental para potencializar os momentos de aprendizagem dos educandos, pois possibilita dinamizar a aula, além de estabelecer novas relações entre o aluno e o conteúdo a ser trabalhado. Nesse sentido, sendo a avaliação da aprendizagem um instrumento que traz elementos e informações sobre a aprendizagem dos alunos, o uso de materiais didáticos específicos para essa modalidade torna-se importante na prática docente, para a coleta de informações sobre o desenvolvimento do educando.

Ainda sobre a questão, a compreensão da necessidade de uma prática educativa específica traz para a discussão outros dois desafios apontados, segundo a professora S03, que são a frequência e a dificuldade de contextualizar o conteúdo com as vivências dos educandos, relacionando as matérias que são dadas em sala de aula com as suas experiências e práticas cotidianas. Além disso, a fala dessa professora reforça a discussão em relação à diferença entre o trabalho com o ensino regular e a EJA.

O desafio maior da EJA é você conseguir segurar frequência. O maior desafio, então você tem que ir adequando todos os dias, todos os dias, se não gostou de uma coisa não adianta insistir, sabe por quê? Aquele que não gostou se você continuar ele não vem mais, então você tem que ir adequando, porque se não realmente eles não ficam, eles evadem mesmo, saem da aula, não ficam mesmo. E tem que ir adequando mesmo, igual você vai trabalhar com material concreto, se eles não gostam não precisa nem insistir, porque eles pensam assim, se amanhã tiver isso eu não vou à aula. Porque com criança é bem assim, olha você não gosta mas a gente tem que fazer. Adulto não, adulto você tem que ter mais jogo de cintura (AS03).

Podemos deduzir por meio da fala dessa professora que a dificuldade de saber o que o aluno tem interesse de aprender e de contextualizar o conteúdo pode contribuir para a infrequência dos alunos na sala de aula, ou mesmo a evasão. Arroyo (2006) afirma que essa diversidade de interesses e expectativas que os alunos têm são de extrema relevância para a prática educativa. Acerca da diversidade, o autor reitera:

Essas diferenças podem ser uma riqueza para o fazer educativo. Quando os interlocutores falam de coisas diferentes, o diálogo é possível. Quando só os mestres têm o que falar não passa de um monólogo. Os jovens e adultos carregam as condições de pensar sua educação como diálogo. Se toda educação exige uma deferência pelos interlocutores, mestres e alunos (as), quando esses interlocutores são jovens e adultos carregados de tensas vivências, essa deferência deverá ter um significado educativo especial (ARROYO, 2006, p. 35) 
Dando continuidade à descrição e à análise sobre os desafios, ressaltamos a diferença destacada pelas docentes entre o processo de ensino e aprendizagem com crianças e adultos, visto que muitas professoras trabalharam muito tempo em outros segmentos, tornando trabalhar com a EJA e suas especificidades um desafio:

É totalmente diferente sabe. Porque a criança ela está desenvolvendo aquilo tudo ali na época certa, o adulto pra mim eu acho assim, ele desenvolveu tudo que teria que desenvolver já desenvolveu, ele não consegue tanto. Eu vou falar assim, toda regra tem exceção, mas ele não consegue. Consegue sim, consegue porque nada é impossível, tudo é possível, mas depende muito dele, ele tem muita dificuldade, tem que ter muita boa vontade, muita força de vontade, pra ele conseguir ir pra frente. É, ele não consegue, tem que ter alguém pra ajudar, mas nunca sabe, tem que estar voltando, é isso aí, é muito diferente da criança para o adulto, nossa, totalmente, tem nada a ver (S01).

Essa fala nos remete também para a reflexão acerca do desenvolvimento intelectual do aluno adulto e contribui para repensarmos o educando da EJA na sua singularidade e diversidade. Tomemos como base a afirmação de Jardilino e Araújo (2014, p.173):

Realçamos aqui que os alunos da EJA são homens e mulheres, atores num dado contexto social e histórico, antes de tudo sujeitos de direitos, que precisam ser considerados numa perspectiva que os compreenda como tais. O ponto de partida precisa ser a compreensão de quem são os alunos da EJA, superando visões restritas e estereotipadas que marcam negativamente a realidade daqueles que não puderam estudar em nosso país.

A compreensão de quem são esses alunos, seus desafios e necessidades se constitui no primeiro passso a ser empreendido pelo docente que se dispõe a ensinar pessoas jovens e adultas, em especial no contexto brasileiro, em que as classes, em geral, são multisseriadas e apresentam grande diversidade geracional. Enfim, é primordial conhecer quem são e do que precisam, ou seja, suas trajetórias de vida e de escolarização. A importância de repensar o ensino para essa modalidade, em vista as especificidades dos sujeitos que integram as classes de EJA, é reforçada por Barcelos (2014, p.144).

A peculiaridade de estarmos trabalhando com jovens e adultos exige uma atenção especial para a forma como os diferentes conteúdos e programas são apresentados e desenvolvidos em uma aula. Quanto maior a possibilidade de diálogo proporcionada pelas atividades programadas com as diversidades presentes, maiores são as chances de participação e de envolvimento do grupo.

Essa atenção às formas de trabalhar os conteúdos pode ser vista na fala da professora S04, que busca conciliar o interesse dos educandos à sua prática dentro da sala de aula, como relata: 
Igual eu tenho um aluno que ele trabalha no depósito de material de construção, uma letra linda, matemática é uma maravilha, português ele fica assim, engatinhando, aí o que que eu fiz: todos os dias depois das nove, nove e pouquinho, começa a decair um pouquinho, muita gente vai embora, porque está cansado e tal, aí eu trabalho com ele português, coisas do dia a dia dele, desde a hora que ele carrega o caminhão, que ele entrega, que ele tem que ler as notinhas, aí eu descobri como que ele lê as notinhas. Aí eu falei, como que tem coisa que você não sabe, como que você consegue distinguir que isso aqui é uma argamassa, por exemplo nível 1, nível 2, aí ele falou comigo assim, que ele grava o logotipo, ele fala assim, professora, é, eu gravo, ele não falou logotipo né, eu que estou falando, ele falou assim eu gravo a figura assim, eu falei é, mais você não erra não, ele falou não. Então eu estou trabalhando com ele cimento, eu fui lá no depósito e peguei tudo que vende lá, falei com a moça me dá aí panfletos, ai estou trabalhando com ele e ele outro dia me relatou e falou: nossa professora, estava descendo na rua assim e já li a placa da rua que eu tinha que ir e já estou conseguindo ler. Então quer dizer, você tem que ter criatividade, você é professor, tem que ser criativo, porque a realidade da noite é uma, do dia é outro, e eu estou tendo sucesso nessa parte (S04).

A fala acima registra como a docente transforma a sua prática, em sala de aula, aproximando-a dos conhecimentos e interesses dos educandos. Um fato tido como dificuldade por algumas professoras interlocutoras nesta investigação tornou-se algo benéfico para a professora S04. Essa professora relata que não somente buscou conhecer a cultura dos seus alunos, como também levou as vivências deles para a sua prática em sala de aula.

A importância de se conhecer o aluno da EJA, bem como o meio em que ele está social e culturalmente inserido, revela caminhos a serem construídos nos processos de ensino e aprendizagem, como destacam Jardilino e Araújo (2015, p.171) quando afirmam que "É preciso, entretanto, conhecer os sujeitos da EJA, suas trajetórias, identificando seu perfil, suas expectativas e vivências, para que eles possam ser considerados na construção de propostas e projetos que venham atender-lhes de maneira mais próxima e específica".

O sentido de aprender nas turmas da EJA, nesta perspectiva, pode ser percebido na relação entre o conteúdo e as necessidades, expectativas e interesses dos alunos. Como pode ser observado, ainda pela narrativa da professora S04: "Então eu estou aproveitando o trabalho dele e ele está adorando, porque o que ele aprende aqui está envolvendo lá, então ele está fazendo a tarefa, esse dever de casa dele".

A prática educativa docente na direção em que os conteúdos trabalhados em sala de aula auxiliam no aprimoramento dos conhecimentos que os educandos já possuem em relação à matemática, geografia, história, enfim, a todas as disciplinas que serão trabalhadas, é 
extremamente relevante, pois grande parte dos conteúdos tem relação direta com os saberes que muitos alunos utilizam em seu cotidiano.

Outro desafio apontado pela professora S03 está relacionado à heterogeneidade de níveis de aprendizagem dentro de cada turma:

Assim, porque eu estou com duas turmas, eu estou com alfabetização e uma turma mais adiantada, então assim são dois níveis ali sabe, de questões de coisas que você tem que estar percebendo, dia a dia, sabe você tem que ter muita atenção com cada aluno. Igual tem os de alfabetização cada um está num nível, então assim fíca complicado sabe (S03).

Essa tem sido uma realidade recorrente na EJA em virtude do número reduzido de alunos nos anos iniciais do Ensino Fundamental, nesta modalidade de ensino; formam-se turmas multisseriadas, nas quais o docente tem de atender, ao mesmo tempo, alunos que se encontram no início do processo de alfabetização e aqueles que se encontram no final do processo, ou seja, alunos de diversos níveis de aprendizagem, com diversas idades. As classes multisseriadas, como ressalta Barcelos (2014), exigem do educador uma nova visão das práticas pedagógicas desenvolvidas com os educandos e, consequentemente, das práticas avaliativas, as quais, considerando a diversidade, se dão de forma mais individualizada, como já mencionado neste estudo.

A compreensão das especificidades da EJA, associada à urgência e necessidade de trabalhar com uma prática educativa diferenciada, coloca um desafio aos educadores da EJA ao se depararem com exigências burocráticas impostas pelas escolas. A relevância desta fala consiste no fato de revelar a emergência da escola rever o seu papel, o currículo, as estratégias de ensino, enfim, de refletir constantemente sobre as singularidades da EJA, para evitar que o educando seja mais uma vez excluído do sistema educacional.

A avaliação é rodeada por leis, pareceres, resoluções, enfim, é imbuída de exigências e determinações definidas tanto para as escolas quanto para os professores. "Tomar consciência desse jogo de poder é essencial à reconstrução do significado da avaliação" (HOFFMAN, 1993, p.11). Esses aspectos evidenciam o caráter político do ato avaliativo e, em consequência, sua reverberação nas ações que acontecem no interior da escola e do sistema educativo. Ainda, segundo a autora, muitos professores não conseguem desenvolver processos avaliativos mediadores, porque estão cercados por normas classificatórias exigidas pela escola.

Essas questões apontadas pelos professores nos levam a refletir sobre a importância de considerar os sujeitos que estão sendo avaliados em sua dimensão integral, deixando de 
ancorar em aspectos puramente classificatórios, herdados de um ensino pautado na ótica seletiva. Portanto, é relevante que esses desafios sejam evidenciados e refletidos para que busquemos intervenções na prática educativa na EJA, como ressalta Barcelos (2014, p.47):

Os desafios que essa modalidade tem colocado aos educadores e educadoras estão a desassossegar e a exigir que aprofundemos os processos de investigação e de reflexão sobre avaliação, que se busque estabelecer interlocuções com diferentes áreas de produção de conhecimento e de saberes, bem como diferentes pensadores.

Os desafios estarão sempre presentes em nossas práticas educativas, contudo, salientamos que algumas estratégias precisam ser consideradas como possibilidades na avaliação dos educandos matriculados na EJA. As participantes da pesquisa revelam essas possibilidades, a partir das suas realidades e considerando as especificidades desta modalidade de ensino, tendo como parâmetro a oferta de uma educação e de um processo avaliativo mais democráticos. Como uma possibilidade de superação desses desafios, está a abertura para o diálogo com os sujeitos que vivenciam o cotidiano escolar.

\section{CONCLUSÃO}

Ao realizarmos essa investigação sobre a avaliação da aprendizagem na Educação de Jovens e Adultos, buscamos aprofundamento teórico e metodológico, para que pudéssemos trazer, a partir de análises e interpretações das informações, dados que contribuíssem para responder aos objetivos propostos por este estudo e para fornecer elementos para que se conheçam algumas práticas avaliativas dos professores da EJA da Região dos Inconfidentes.

Os resultados encontrados indicaram que os sujeitos envolvidos na pesquisa revelaram os desafios e possibilidades da avaliação na Educação de Jovens e Adultos e, ao dialogarmos sobre os desafios do ato avaliativo na prática docente, algumas professoras apontaram, também, algumas possibilidades de trabalho com a EJA: a abertura para o diálogo com os educandos e a humildade dos docentes ao compreenderem que aqueles que ensinam também aprendem com a turma.

Essas professoras demonstraram reconhecer a importância de trazer para a sala de aula as vivências e experiências dos alunos, compartilhando-as por meio do diálogo e da relação de parceria estabelecida entre as docentes e os educandos. Além disso, buscaram relacionar as atividades pedagógicas aos saberes cotidianos dos educandos, por meio de uma prática mais 
contextualizada e significativa, sem desconsiderar a afetividade e o incentivo constantes, ações necessárias quando se deseja construir uma prática educativa mais democrática.

Vale ressaltar que os desafios na EJA são complexos e não deixarão de existir, contudo, é possível fazer algumas proposições de atuação nessa modalidade, com o foco em ações mais democráticas, tais como a abertura ao diálogo dentro da sala de aula para a construção das práticas avaliativas, a consideração do contexto dos educandos, a responsabilização e o compromisso tanto do educador como do aluno com a sua formação, a relação de amorosidade dentro do processo educacional, a construção de procedimentos avaliativos consoante as situações cotidianas da sala de aula.

A presente investigação indica que a construção de uma avaliação mais qualitativa e democrática na EJA, dada as suas especificidades, só será possível a partir do diálogo e da amorosidade dos envolvidos no contexto escolar. Todo ato avaliativo só terá sentido se compreendido e realizado de acordo com um corpo teórico, segundo nossa análise, consciente, e com o fim de acompanhamento da aprendizagem do educando e da intervenção necessária. Dessa forma, faz-se necessário reforçar a avaliação como um instrumento de suma importância na prática educativa docente, aproximando-a de uma prática de investigação e intervenção.

\section{REFERÊNCIAS}

ARROYO, M. G. Formar educadores e educadoras de jovens e adultos. In: SOARES, Leôncio (org.) Formação de educadores de jovens e adultos. Belo Horizonte: Autêntica/Secad-MEC/Unesco, 2006.

BARCELOS, V. Avaliação na Educação de Jovens e Adultos: uma proposta solidária e cooperativa. Petrópolis, RJ: Vozes, 2014.

BARDIN, L. Análise de Conteúdo. São Paulo: Edições 70, 2011.

BOGDAN, R. ; BIKLEN, S. Investigação qualitativa em educação: uma introdução à teoria e aos métodos. Porto: Porto Editora, 1994.

ESTEVES, M. M. A análise de conteúdo. In: LIMA, J. A. ; PACHECO, J. A. (orgs). Fazer investigação: contributos para a elaboração de dissertações e teses. Porto: Porto Editora, 2006.

GUIMARÃES, A.; MARTINS, M. Práticas pedagógicas nos anos iniciais do Ensino Fundamental da Educação de Jovens e Adultos no Município de Mariana: refletindo 
Seção: Teorias e práticas pedagógicas - Artigo original

17

sobre a atuação do professor em classes multisseriadas. Mariana. 2014. Monografia.

Universidade Federal de Ouro Preto, 2014.

HOFFMAN, J. Avaliação: mito e desafio, uma perspectiva construtivista. 9. ed. Porto Alegre: Educação e Realidade Revistas e Livros, 1993.

JARDILINO, J.; ARAÚJO, R. M. B. Educação de Jovens e Adultos: sujeitos, saberes e práticas. São Paulo: Cortez, 2014. (Coleção Docência em Formação).

LIMA, J. Ética na investigação. In: LIMA, J. A.; PACHECO, J. A. (orgs.). Fazer investigação: contributo para elaboração de dissertações e teses. Porto: Porto Editora, 2006.

LUCKESI, C. Avaliação da aprendizagem, componente do ato pedagógico. São Paulo: Cortez, 2011.

VASCONCELLOS, C. dos S. Avaliação: concepção dialética-libertadora do processo de avaliação escolar. 18. ed. São Paulo: Libertad, 2008. 